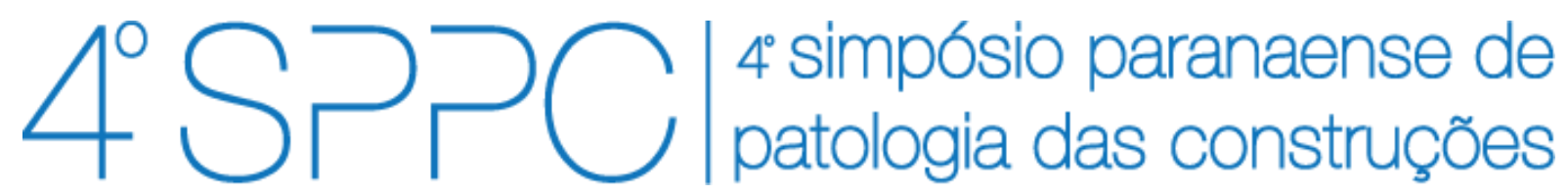

ISSN 2526-7248 artigo n. 4SPPC111, pp. 80-90, 2019

\title{
Microestrutura de armaduras em processo de corrosão natural: estudo de caso em barras de aço pertencentes à antigas fundações do ITA
}

\author{
Schmoeller, Francieli ${ }^{1}$; Lima, Maryangela Geimba de ${ }^{2}$ \\ ${ }^{1}$ Mestranda, Instituto Tecnológico de Aeronáutica, francieli.schmoeller@gmail.com \\ ${ }^{2}$ Professora Dra, Instituto Tecnológico de Aeronáutica, magdlima@gmail.com
}

Resumo: A corrosão, manifestação que mais degrada o aço, faz-se muito presente na deterioração de estruturas de concreto armado, limitando sua durabilidade e podendo levá-la ao colapso. Ainda, de acordo com estudos recentes, a corrosão é responsável por cerca de 4\% do PIB anual com custos de recuperação no Brasil. Dessa forma, entendese de grande valia a melhor compreensão do processo de corrosão de barras de aço por envelhecimento natural, através de uma análise microestrutural. Assim, realizou-se o estudo em três barras de aço liso, com 15,88 mm de diâmetro, que pertenciam à armaduras de espera das antigas fundações do prédio da Ala Zero do ITA, ao qual permaneceram enterradas por cerca de 60 anos, até o ano de 2008, quando as amostras foram coletadas e armazenadas em laboratório. O estudo abordou dois aspectos distintos: a análise macro e microestrutural, de forma a obter um exame do material e do processo de corrosão. Para isso, realizou-se análise visual ao longo da extensão das barras, bem como a avaliação por microscopia óptica e microscopia eletrônica de varredura, que permitiu verificar a irregularidade do formato e tamanho dos grãos, visualização dos contornos de grãos, pontos de óxidos intergranulares, como também, a espessura da crosta de corrosão formada na superfície das barras. Ainda, foi possível analisar que, após cerca de 70 anos de deterioração, as barras não perderam significativamente sua seção.

Palavras-chave: Barras de aço, corrosão, microestrutura.

Abstract: Corrosion is the manifestation more degrades the steel and is very present in the deterioration of reinforced concrete structures, limiting their durability and may lead to collapse. Also, according to recent studies, corrosion accounts for about $4 \%$ of annual GDP with recovery costs in Brazil. Thus, is very important to understand the process of corrosion of steel bars by natural aging, through of the microstructural analysis. Therefore, the study was implemented on three steel bars, with $15.88 \mathrm{~mm}$ in diameter that belonged to the steels of the old foundations of the ITA Zero Wing building, to which they remained buried for about 60 years, until the year 2008, when the samples were collected and stayed in the laboratory. The study addressed two distinct aspects: the macro and microstructural analysis, in order to obtain an examination of the material and the corrosion process. For this, a visual analysis was carried out along the extension of the bars, as well as the evaluation by optical microscopy and scanning electron microscopy, which allowed to verify the irregularity of the shape and size of the grains, visualization of grain contours, intergranular oxide points, as well as the thickness of the corrosion crust formed on the surface of the bars. Moreover, it was possible to analyze that, after about 70 years of deterioration, the bars did not significantly lose their section of the bars.

Keywords: Steel bars, corrosion, microstructure. 
SCHMOELLER, F; LIMA, M.G.; MICROESTRUTURA DE ARMADURAS EM PROCESSO DE CORROSÃO NATURAL: ESTUDO DE CASO EM BARRAS DE AÇO PERTENCENTES À ANTIGAS FUNDAÇÕES DO ITA. $4^{\circ}$ Simpósio Paranaense de Patologia das Construções (40 SPPC), artigo 4SPPC111, pp. 80 - 90, 2019. DOI: 10.4322/2526-7248.031

\section{Introdução}

O concreto armado é muito utilizado como elemento estrutural no Brasil, ocupando grande importância e aplicação na construção civil do país. Entretanto, a incidência de manifestações patológicas neste tipo de estrutura tornou-se recorrente nos últimos anos, sobretudo problemas relacionados a corrosão de armadura.

Dentre as deteriorações em estruturas de concreto armado, a corrosão de armaduras tem maior ocorrência e é a que causa maiores prejuízos econômicos no Brasil (CARMONA) [1]. Segundo a USP/IZA apud Goes [2], o gasto anual decorrente da corrosão chegou a 4\% do Produto Interno Bruto (PIB) nacional em 2017, ou seja, cerca de $\mathrm{R} \$ 264$ bilhões.

A corrosão pode ser classificada como a interação destrutiva de um material com o seu meio, e comumente ocorre por natureza eletroquímica, movida em meio aquoso, com reações de oxidação e redução, formando uma corrente elétrica e uma corrente iônica, desenvolvendo assim, óxidos e hidróxidos de ferro, nomeados como produtos de corrosão. Ainda, a corrosão depende também do pH do meio e é basicamente ele o responsável por potencializar a corrosão. De acordo com Mehta e Monteiro [3], quando o pH do concreto passa a ser menor que 11,5, a película passivadora é destruída, o que propicia o início da corrosão.

Dessa forma, pode ser estabelecida uma relação em função do $\mathrm{pH}$, que são representados nos diagramas $\mathrm{E}-\mathrm{pH}$, conhecidos como diagrama de Pourbaix. Neste diagrama, são estabelecidas as condições de $\mathrm{pH}$ em relação ao potencial que leva o material à três situações distintas: a região de imunidade, onde independente do $\mathrm{pH}$, o aço possui um potencial de corrosão muito baixo, encontrando-se resguardado; a área de passivação, onde a armadura possui a camada protetora; e à corrosão, localizado em circunstâncias de $\mathrm{pH}$ mais ácido, onde ocorre a despassivação da armadura, e consequentemente, sua deterioração.

O período de iniciação ou despassivação, é o tempo decorrido para os agentes agressivos impetrarem na armadura. Após, inicia-se o período de propagação, onde a presença de oxigênio e umidade, e o fator temperatura alavancam a corrosão até um nível aceitável, ou seja, até fazer-se necessário algum reparo. Através da corrosão, o detrimento da proteção da armadura prejudica significativamente a durabilidade e a vida útil da estrutura, podendo comprometê-la e levá-la ao colapso.

Os materiais reagem de forma diferente aos agentes agressivos, ao qual possuem uma velocidade de deterioração particular, já que existem diversos processos de fabricação e tratamentos, resultando em diferentes características mecânicas e químicas. O aço é um produto siderúrgico, obtido por via líquida, basicamente constituído de ferro e carbono (Fe-C), com teor de carbono admissível de até $2 \%$, além de contar com pequenas quantidades de outros elementos, como o manganês, o enxofre, o fósforo e o silício.

Entre os grupos de materiais, os metálicos destacam-se devido a sua extensiva utilização. Na tabela periódica atual, quase $75 \%$ dos elementos encontrados na natureza têm caráter metálico preponderante. Segundo Padilha e Ambrozio Filho [4], a microestrutura de materiais cristalinos, que é o caso dos metais, é formada por defeitos, como vazios, trincas, contornos de grãos e subgrãos, dentre outros. 
Uma análise microestrutural é utilizada quando o material passa a ser estudado através de grandeza microscópica, não visível a olho nu. A aplicação de técnicas para avaliação da microestrutura vem se tornando cada vez mais frequente no estudo da ciência dos materiais, principalmente com o uso de Microscopia Óptica (MO), Microscopia Eletrônica de Varredura (MEV) ou de Transmissão (MET).

A preocupação com a qualidade e desempenho das estruturas resultam em pesquisas cada vez mais aprofundadas, entendendo-se assim, a importância do estudo da microestrutura de barras de aço com 70 anos de idade, que estão em processo de corrosão por envelhecimento natural, com o intuito de entender melhor o processo de degradação.

\section{Materias e métodos}

Neste capítulo serão abordados os materiais que compuseram a amostra deste estudo, e a metodologia empregada para a realização dos ensaios estabelecidos.

\subsection{Materiais}

As antigas fundações do prédio da Ala Zero do ITA eram formadas por estacas moldadas in loco, blocos de fundações e armaduras de espera. No presente trabalho foram estudadas três barras de espera dos blocos de fundações, que ficaram protegidas por uma caixa de alvenaria com areia, e coberta com solo (SILVA) [5].

Estes elementos estruturais permaneceram enterrados por um período de aproximadamente 60 anos, abrangendo desde sua construção até o ano de 2008, quando as amostras foram coletadas e armazenadas no Laboratório de Materiais do Departamento de Engenharia Civil do ITA. Hoje, estas barras têm cerca de 70 anos de envelhecimento natural.

De acordo com os projetos executivos das fundações, as armaduras de espera utilizadas na obra eram constituídas de vergalhões lisos com bitolas de 15,88 mm e 19,05 mm de diâmetro, e cada bloco de fundação contava com 6 barras de espera. Para compor a amostra deste estudo, foram selecionadas 3 armaduras de espera com diâmetro nominal de15,88 mm, correspondentes as barras B1, B2 e B6 pertencentes ao bloco de fundação B:

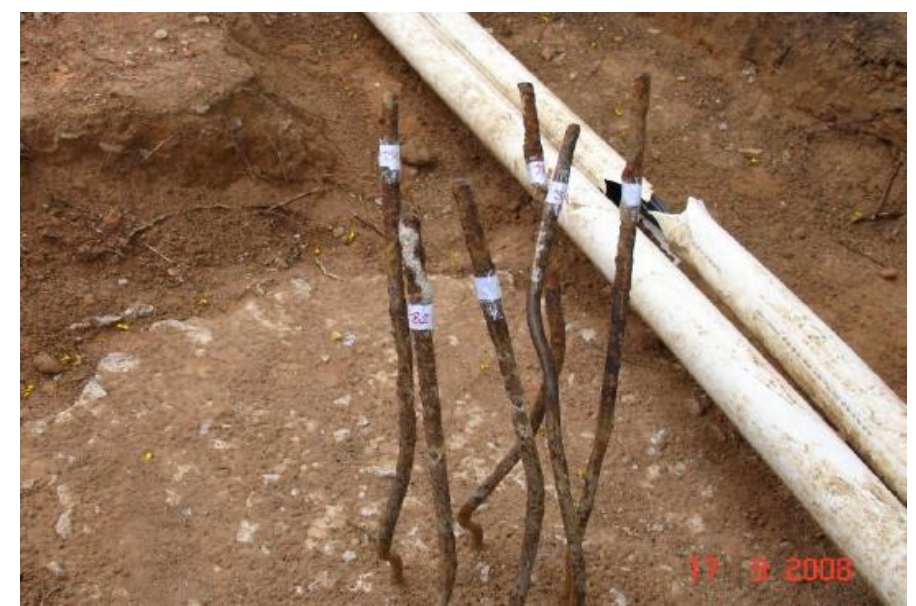

Figura 1: Vergalhões de espera do bloco B (SILVA) [5] 


\subsection{Métodos}

A metodologia aplicada neste trabalho teve o intuito de ensaiar as amostras para análise do estado de corrosão em duas percepções distintas: macro e microestrutural, que serão descritos na sequência.

\subsubsection{Métodos para análise macroestrutural}

$\mathrm{Na}$ análise macroestrutural, as amostras foram cortadas com comprimento total de $200 \mathrm{~mm}$, e após, realizou-se a verificação superficial da textura, cor da barra e a estimativa de óxidos e hidróxidos na sua crosta de corrosão, assim como a leitura da seção atual com auxílio do micrômetro.

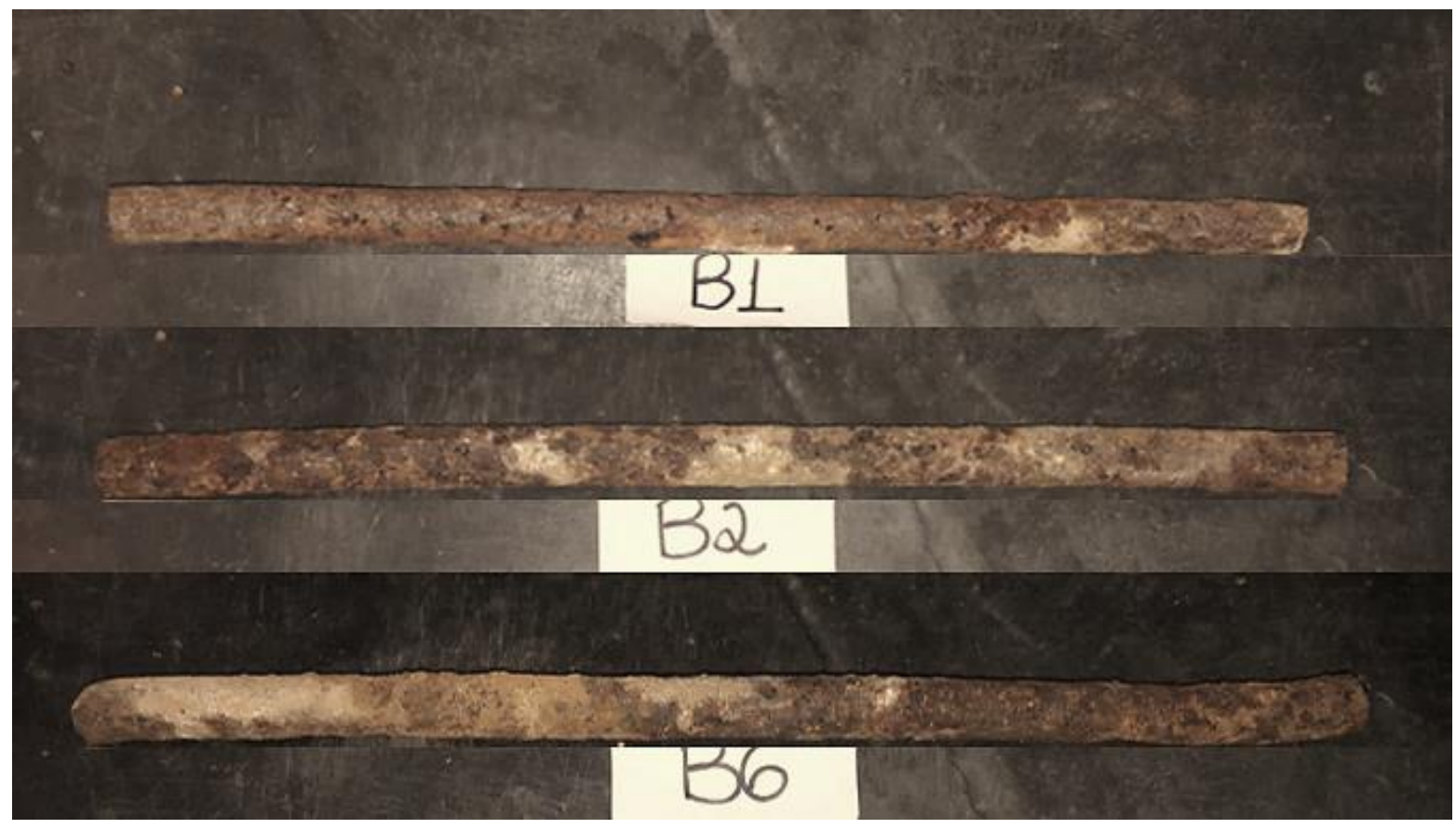

Figura 2: Armaduras de espera B1, B2 e B6 após corte com disco (A AUTORA, 2019)

A análise superficial da textura buscou o estado geral da armadura possível de ser observado visualmente, como algumas cavidades e incrustações oriundas da corrosão. A cor e a estimativa de óxidos e hidróxidos foram caracterizadas através das prováveis reações durante o processo corrosivo, mostrado na Tabela 1. De acordo com Helene [6], pela diferença de cores nas barras é possível estimar as reações e os produtos formados pelo processo de corrosão.

Já para a leitura da seção atual, cada barra foi dividida em 10 seções, e em cada seção foram realizadas 4 leituras em ângulos pré-estabelecidos, buscando analisar o real diâmetro das amostras, após cerca de 70 anos de degradação, com a utilização de um paquímetro de ponta cônica. 


\subsubsection{Métodos para análise microestrutural}

$\mathrm{Na}$ análise da microestrutura da barra, foram realizadas avaliações por meio da microscopia óptica (MO) e microscopia eletrônica de varredura (MEV), para averiguar os grãos e seus contornos, bem como a camada de corrosão formada na borda das amostras. Para tanto, utilizou-se o microscópio óptico modelo Axio, da marca Zeiss, e o MEV de bancada, da marca Tescan, modelo Vega3.

Para a análise microestrutural, primeiramente foi realizada a preparação metalográfica das amostras na seguinte sequência: a barra foi cortada em amostras de $10 \mathrm{~mm}$; foi realizado o embutimento com baquelite para preservar as bordas da amostra; o lixamento gradual e o polimento com alumina, de modo a garantir um bom grau de acabamento e, por fim, feito o ataque químico com Nital 5\%, possibilitando revelar características que não são visíveis apenas com o polimento.

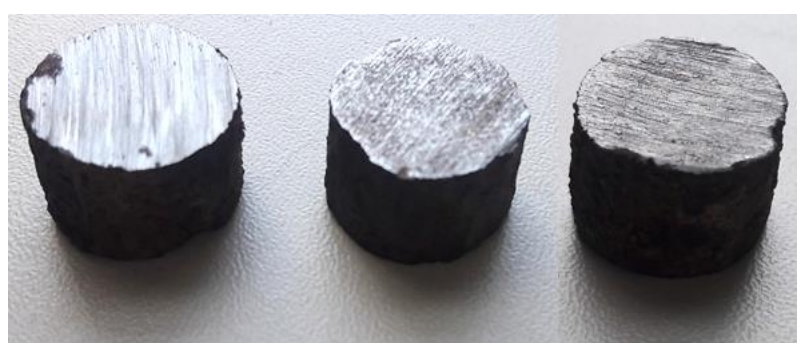

(a)

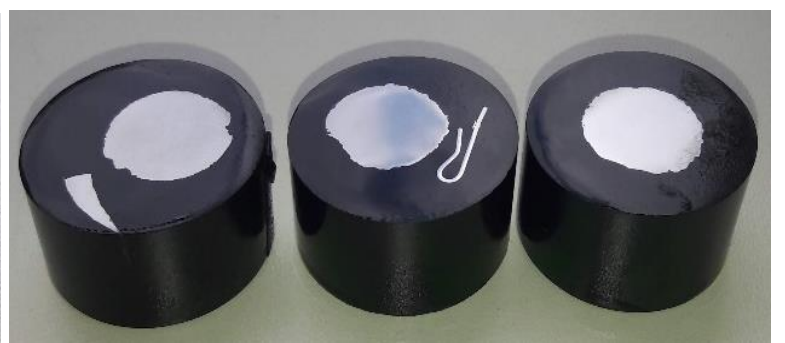

(b)

Figura 3: Armaduras de espera B1, B2 e B6: (a) após corte com disco; (b) após o embutimento e polimento (A AUTORA, 2019)

\section{Resultados e Discussões}

Neste capítulo serão apresentados e analisados os resultados obtidos pela metodologia descrita no Capítulo 2.

\subsection{Análise Macroestrutural}

Através da análise macroestrutural, foi possível visualizar que o processo de corosão percorre ao longo de toda a extensão das barras, ação típica da corrosão uniforme, acarretando em superfícies com deformações e cavidades de tamanhos distintos, com alguns desgastes mais profundos.

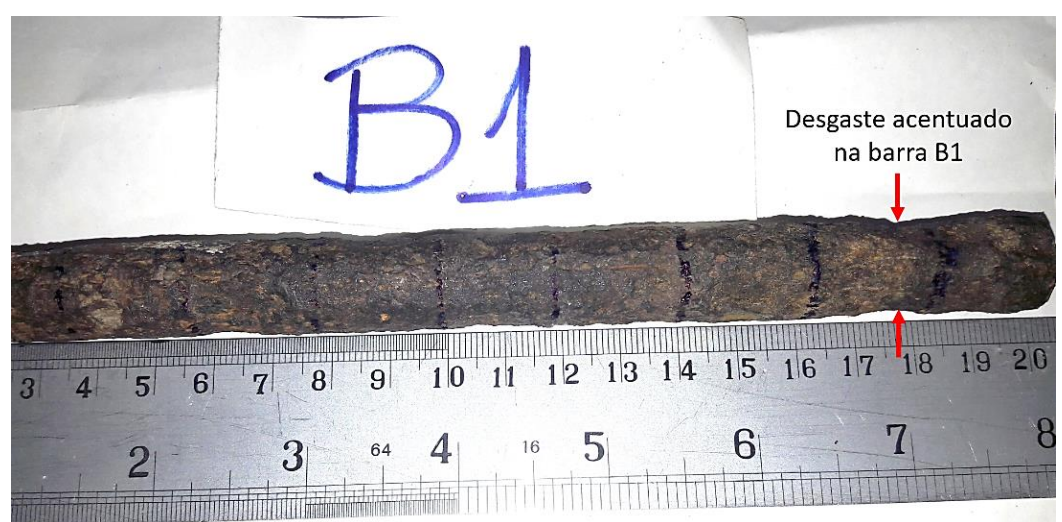


Figura 4: Amostra B1 com desgaste acentuado (A AUTORA, 2019)

Como já mencionado, a corrosão em meio aquoso é a mais comum, já que a maioria dos fenômenos de corrosão surgem em estruturas expostas no meio ambiente e a presença de água favorece e a torna o principal solvente no processo de corrosão, propiciando a formação de diversos óxidos e hidróxidos, seguindo as reações prováveis apresentadas por Helene [6] na Tabela 1, a seguir:

Tabela 1: Reações prováveis durante o processo corrosivo

\begin{tabular}{|c|c|c|}
\hline Região & Reação provável & $\begin{array}{l}\text { Características do } \\
\text { produto formado }\end{array}$ \\
\hline & $2 \mathrm{Fe}+\mathrm{O}_{2}+2 \mathrm{H}_{2} \mathrm{O} \rightarrow 2 \mathrm{Fe}\left(\mathrm{OH}_{2}\right)$ & Ferrugem \\
\hline $\begin{array}{c}\text { Zona } \\
\text { anódica }\end{array}$ & $2 \mathrm{Fe} \rightarrow 2 \mathrm{Fe}^{2+}+4 \mathrm{e}^{-}$ & Oxidação do ferro \\
\hline $\begin{array}{c}\text { Zona } \\
\text { catódica }\end{array}$ & $2 \mathrm{H}_{2} \mathrm{O}+\mathrm{O}_{2}+4 \mathrm{e}^{-} \rightarrow 4 \mathrm{OH}^{-}$ & Redução do oxigênio \\
\hline \multirow{5}{*}{$\begin{array}{l}\text { Superfície } \\
\text { da barra ou } \\
\text { eletrólito }\end{array}$} & $2 \mathrm{Fe}^{2+}+4 \mathrm{OH}^{-} \rightarrow 2 \mathrm{Fe}(\mathrm{OH})_{2}$ & $\begin{array}{l}\text { Hidróxido ferroso, } \\
\text { fracamente solúvel, de } \\
\text { cor marrom }\end{array}$ \\
\hline & $2 \mathrm{Fe}^{2+}+4 \mathrm{OH}^{-} \rightarrow 2 \mathrm{FeO} \cdot \mathrm{H}_{2} \mathrm{O}$ & $\begin{array}{c}\text { Óxido ferroso hidratado, } \\
\text { expansivo, de cor } \\
\text { marrom }\end{array}$ \\
\hline & $4 \mathrm{Fe}(\mathrm{OH})_{2}+2 \mathrm{H}_{2} \mathrm{O}+\mathrm{O}_{2} \rightarrow 4 \mathrm{Fe}(\mathrm{OH})_{3}$ & $\begin{array}{c}\text { Hidróxido férrico, } \\
\text { expansivo, avermelhado }\end{array}$ \\
\hline & $3 \mathrm{Fe}+8 \mathrm{OH}^{-} \rightarrow \mathrm{Fe}_{3} \mathrm{O}_{4}+8 \mathrm{e}^{-}+4 \mathrm{H}_{2} \mathrm{O}$ & $\begin{array}{c}\text { Óxido de característica } \\
\text { mista - férrico e ferroso, } \\
\text { na cor preta }\end{array}$ \\
\hline & $4 \mathrm{Fe}(\mathrm{OH})_{2}+2 \mathrm{H}_{2} \mathrm{O}+\mathrm{O}_{2} \rightarrow 4 \mathrm{Fe}_{2} \mathrm{O}_{3} \cdot \mathrm{H}_{2} \mathrm{O}$ & $\begin{array}{l}\text { Óxido férrico hidratado, } \\
\text { expansivo }\end{array}$ \\
\hline
\end{tabular}

(GOMES e BARRETO; POPOVICS; apud HELENE) [6]

De modo geral, a amadura apresenta em sua superfície a cor marrom-alaranjada, caracteristica do processo de corrosão, com algumas outras cores pontuais resultantes de produtos da oxidação das prováveis reações elencadas por Helene [6], que podem ser observados na Figura a seguir: 


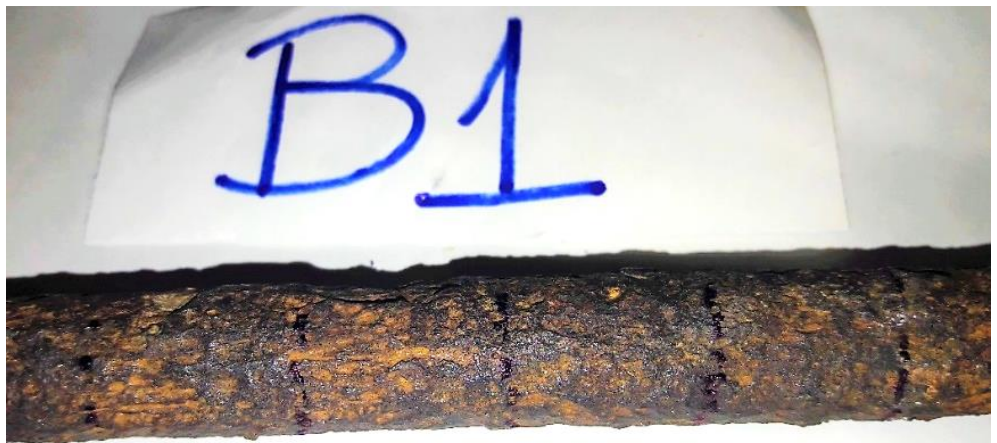

(a)
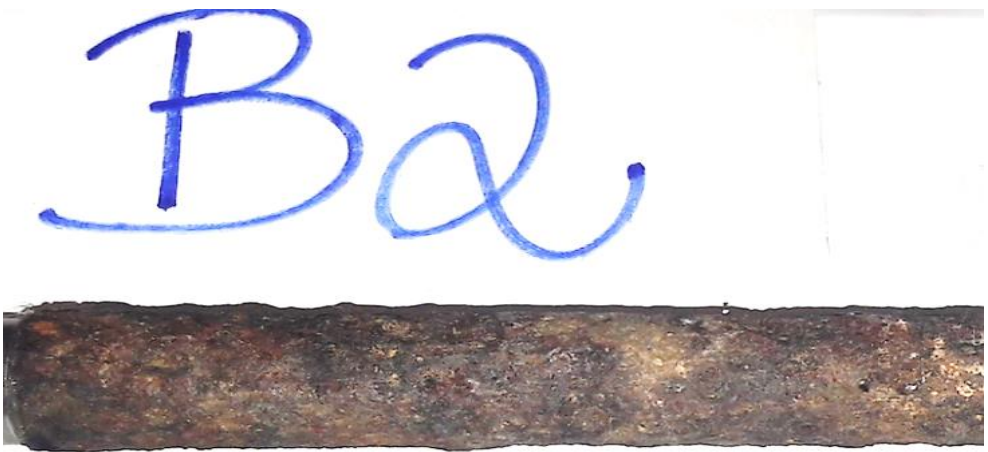

(b)

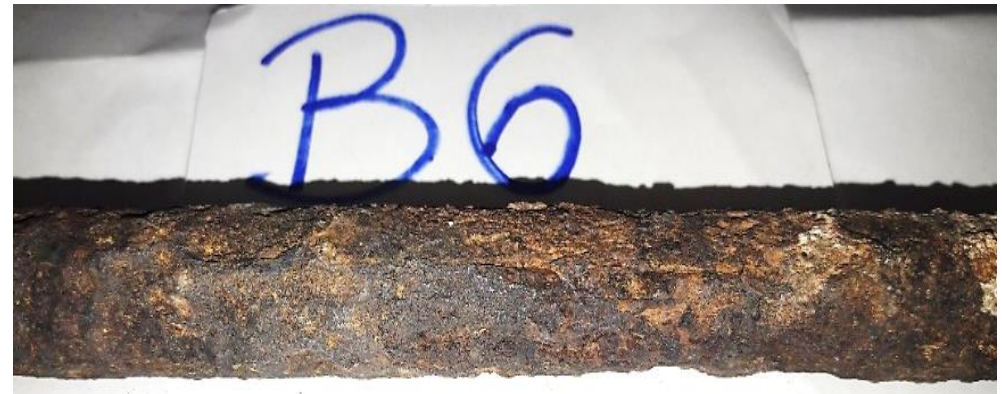

(c)

Figura 5: Amostras com as possíveis reações características da corrosão e os desgastes provocados pela corrosão: (a) amostra B1; (b) amostra B2; (c) amostra B6 (A AUTORA, 2019)

$\mathrm{Na}$ análise visual, foram encontrados pontos em tom avermelhado, tratando-se possivelmente do hidróxido férrico $\left[4 \mathrm{Fe}\left(\mathrm{OH}_{3}\right)\right]$, regiões em marrom escuro, típico de óxido/hidróxido ferroso $\left[2 \mathrm{Fe}\left(\mathrm{OH}_{2}\right)\right.$ ou $\left.2 \mathrm{FeO} . \mathrm{H}_{2} \mathrm{O}\right]$, assim como pontos na cor preta, possivelmente tratando-se de óxido de caracterrística mista (férrico e ferroso) $\left[\mathrm{Fe}_{3} \mathrm{O}_{4}\right.$ $\left.+8 \mathrm{e}^{-}+4 \mathrm{H}_{2} \mathrm{O}\right]$.

A Tabela 2 a seguir, apresenta os resultados da medição com o micrômetro de ponta cônica, das 10 seções nos 4 ângulos estabelecidos (ângulos $0^{\circ}, 45^{\circ}, 90^{\circ}$ e $135^{\circ}$ ), obtendo uma média para cada seção, e uma média total para cada amostra. 
Tabela 2: Leitura das seções das amostras B1, B2 e B6

\begin{tabular}{|c|c|c|c|c|c|c|}
\hline \multicolumn{7}{|c|}{ Leitura com micrômetro } \\
\hline \multicolumn{7}{|c|}{ Barra B1 } \\
\hline Seção & Comp. (mm) & $\varnothing 0^{\circ}$ & $\varnothing 45^{\circ}$ & $\varnothing 90^{\circ}$ & $\varnothing 135^{\circ}$ & Média da seção \\
\hline 1 & 20 & 15,335 & 14,893 & 14,327 & 13,578 & 14,533 \\
\hline 2 & 40 & 15,680 & 13,850 & 14,780 & 14,296 & 14,652 \\
\hline 3 & 60 & 15,787 & 14,027 & 15,378 & 15,415 & 15,152 \\
\hline 4 & 80 & 14,966 & 14,488 & 15,700 & 15,574 & 15,182 \\
\hline 5 & 100 & 15,832 & 14,208 & 15,345 & 14,590 & 14,994 \\
\hline 6 & 120 & 15,015 & 14,907 & 15,025 & 15,498 & 15,111 \\
\hline 7 & 140 & 14,009 & 12,570 & 13,544 & 14,237 & 13,590 \\
\hline 8 & 160 & 13,228 & 14,914 & 12,703 & 14,725 & 13,893 \\
\hline 9 & 180 & 12,308 & 14,757 & 12,638 & 11,665 & 12,842 \\
\hline 10 & 200 & 14,829 & 12,880 & 15,122 & 15,938 & 14,692 \\
\hline \multirow{2}{*}{\multicolumn{7}{|c|}{ Média total }} \\
\hline & & & & & & \\
\hline Seção & Comp. (mm) & $\varnothing 0^{\circ}$ & $\varnothing 45^{\circ}$ & $\varnothing 90^{\circ}$ & $\varnothing 135^{\circ}$ & Média da seção \\
\hline 1 & 20 & 14,456 & 15,438 & 13,343 & 14,029 & 14,317 \\
\hline 2 & 40 & 15,540 & 15,883 & 14,185 & 14,463 & 15,018 \\
\hline 3 & 60 & 14,929 & 14,459 & 14,341 & 15,550 & 14,820 \\
\hline 4 & 80 & 15,220 & 14,986 & 15,398 & 15,506 & 15,278 \\
\hline 5 & 100 & 15,918 & 16,217 & 14,815 & 15,317 & 15,567 \\
\hline 6 & 120 & 15,832 & 15,683 & 14,104 & 15,765 & 15,346 \\
\hline 7 & 140 & 13,372 & 15,003 & 12,894 & 14,762 & 14,008 \\
\hline 8 & 160 & 15,753 & 15,274 & 14,711 & 14,470 & 15,052 \\
\hline 9 & 180 & 15,937 & 14,537 & 14,940 & 14,657 & 15,018 \\
\hline 10 & 200 & 15,488 & 15,222 & 14,555 & 14,502 & 14,942 \\
\hline \multicolumn{7}{|c|}{ Média total } \\
\hline \multicolumn{7}{|c|}{ Barra B6 } \\
\hline Seção & Comp. (mm) & $\varnothing 0^{\circ}$ & $\varnothing 45^{\circ}$ & $\varnothing 90^{\circ}$ & $\varnothing 135^{\circ}$ & Média da seção \\
\hline 1 & 20 & 14,105 & 15,882 & 15,035 & 13,812 & 14,709 \\
\hline 2 & 40 & 14,840 & 15,171 & 14,824 & 14,737 & 14,893 \\
\hline 3 & 60 & 14,220 & 15,335 & 13,734 & 15,062 & 14,588 \\
\hline 4 & 80 & 14,538 & 14,439 & 15,525 & 15,354 & 14,964 \\
\hline 5 & 100 & 15,039 & 15,351 & 15,061 & 14,433 & 14,971 \\
\hline 6 & 120 & 15,579 & 13,100 & 14,538 & 14,268 & 14,371 \\
\hline 7 & 140 & 14,468 & 15,261 & 12,512 & 13,824 & 14,016 \\
\hline 8 & 160 & 14,891 & 14,824 & 13,959 & 14,397 & 14,518 \\
\hline 9 & 180 & 16,361 & 15,269 & 15,402 & 15,229 & 15,565 \\
\hline 10 & 200 & 15,550 & 15,252 & 15,016 & 14,277 & 15,024 \\
\hline \multicolumn{6}{|c|}{ Média total } & 14,726 \\
\hline
\end{tabular}

$\mathrm{Na}$ Tabela 2, os pontos em que o aço ultrapassa o valor do diâmetro original de 15,88 $\mathrm{mm}$, entende-se que o processo de corrosão resultou no surgimento de camadas localizadas, por meio do qual, o cátion metálico resultante deste processo reage com 
os elementos presentes no meio como o oxigênio, a hidroxila, o enxofre e o cloreto, depositando-se na superfície. Além disso, o processo de oxidação do aço resulta em um aumento do seu volume, permitindo sua expansão, e consequentemente, aumentando seu diâmetro. Nos pontos em que o diâmetro da amostra se apresenta menor que 15,88 mm, são encontradas as cavidades e os desgastes mais acentuados do aço, originadas pela perda de massa da barra.

Verificando a média total de cada amostra, é possível concluir que, as barras atualmente encontram-se com seção abaixo do diâmetro original de fabricação, de $15,88 \mathrm{~mm}$. A menor média total foi lida na amostra B1 com 14,464 mm, diferença de $8,92 \%$ na perda do diâmetro médio total, seguido da B6 com 14,762 mm, e com $14,936 \mathrm{~mm}$ a barra B2.

Ainda, ao analisar cada seção medida, os valores resultantes são ainda mais baixos. Na seção 9 a 135 da amostra B1, foi obtido o diâmetro de 11,665 mm, o menor encontrado entre as leituras realizadas. Ao compará-lo ao diâmetro original, a perda de seção neste ponto foi de $26,54 \%$. Na barra B2, o menor diâmetro encontrado foi de $12,894 \mathrm{~mm}$, perda de $18,80 \%$, e na armadura B6, o maior desgaste lido foi de $12,512 \mathrm{~mm}$, diminuição de $21,21 \%$ comparado aos $15,88 \mathrm{~mm}$ originais.

\subsection{Análise Microestrutural}

$\mathrm{Na}$ análise microestrutural, foram realizados ensaios por microscopia óptica (MO), para uma análise generalizada e por microscopia eletrônica de varredura (MEV), para um estudo mais detalhado, apresentados na sequência.

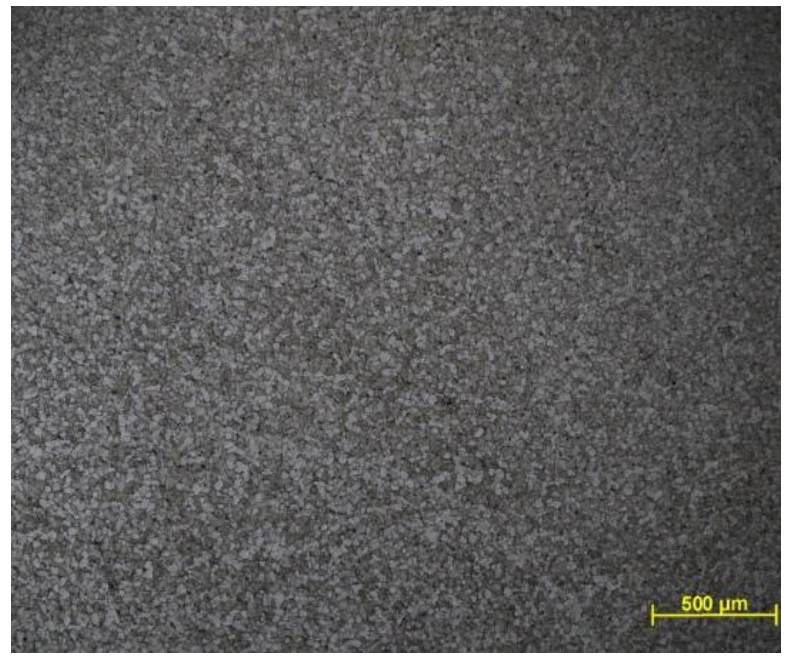

(a)

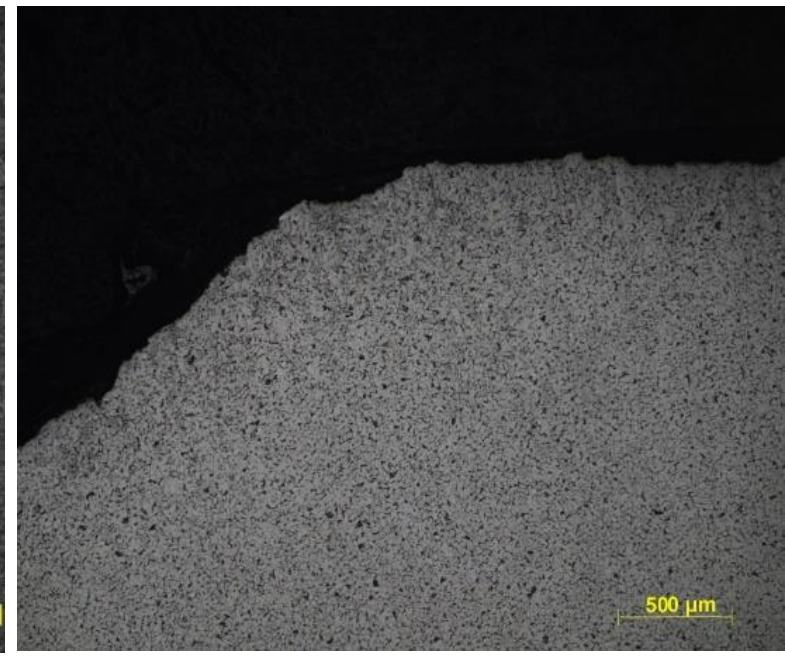

(b)

Figura 6: Imagens do microscópio óptico, com ampliação de 50X (a) no centro da amostra; (b) da borda corroída (A AUTORA, 2019)

De uma forma geral, a Figura 6 (a) mostra a estrutura e a homogeneidade dos grãos no centro da amostra. Na imagem (b), com o embutimento da baquelite, ficou bem nítida a irregularidade da borda, decorrido da perda de massa da barra, oriunda da corrosão. Ainda, é possível comparar as imagens e notar a homogeneidade dos grãos do núcleo e da extremidade do corpo-de-prova. Para uma análise mais aprofundada do material, fora realizado o ensaio com o MEV, utilizando as mesmas amostras que foram preparadas para o ensaio da MO anterior. 

Construções (40 SPPC), artigo 4SPPC111, pp. 80 - 90, 2019. DOI: 10.4322/2526-7248.031

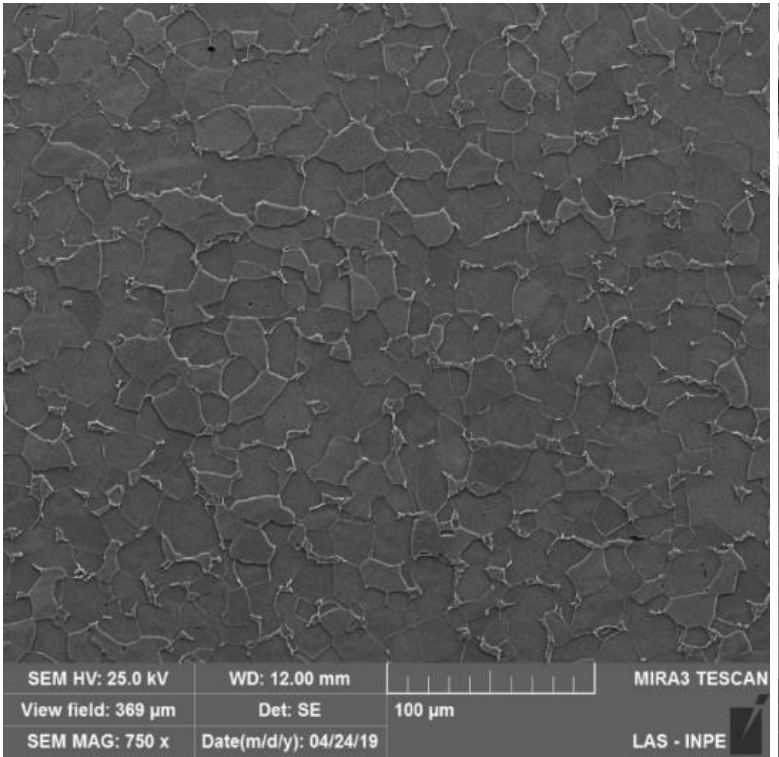

(a)

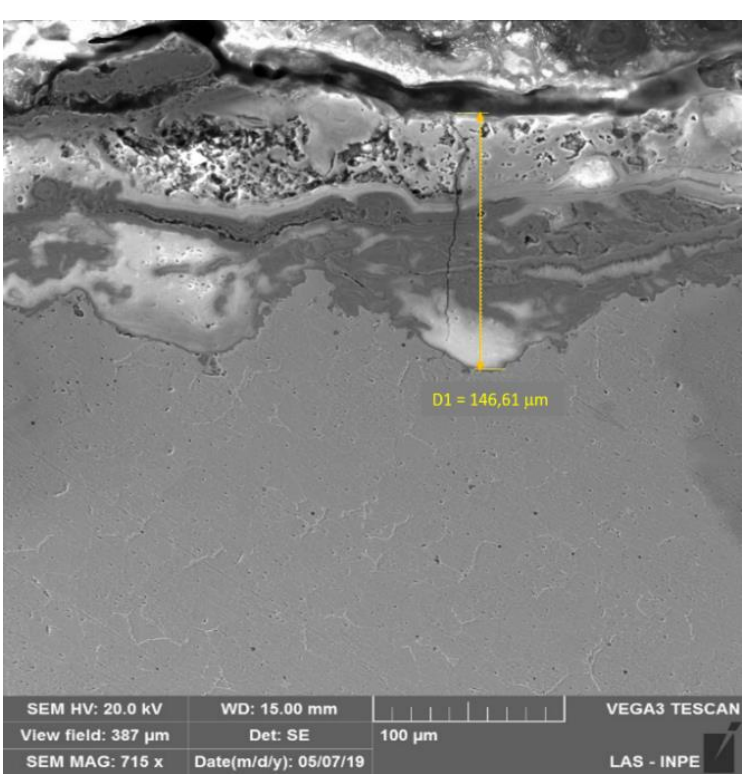

(b)

Figura 7: Imagens do MEV (a) no centro da amostra com ampliação de 750X; (b) da borda corroída com ampliação de 715X (A AUTORA, 2019)

A Figura 7 (a) foi obtida através do detector secundário, permitindo verificar a configuração do material de forma ampla, mostrando que, independente da homogeneidade que os materiais metálicos apresentam, cada grão possui um formato distinto e tamanhos desproporcionais, revelando grãos irregulares. A Figura (b) permite a análise e medição da crosta de corrosão, onde o maior comprimento da profundidade de corrosão foi de 146,61 $\mu \mathrm{m}$, que apresenta-se com espessura desordenada e diversas microfissuras e vazios, provenientes da corrosão ao longo do período de envelhecimento natural.

\section{Conclusões}

$\mathrm{Na}$ análise macroestrutural, por meio da avaliação visual, as amostras apresentam corrosão uniforme, com cavidades e encrustações de tamanhos diversos, e algumas seções com desgaste mais evidenciado. Na superfície das barras, foram observados pontos com diferentes tonalidades: em tom avermelhado, tratando-se possivelmente do hidróxido férrico [4Fe $\left.\left(\mathrm{OH}_{3}\right)\right]$, em marrom escuro, típico de óxido/hidróxido ferroso [2Fe $\left(\mathrm{OH}_{2}\right)$ ou $2 \mathrm{FeO} . \mathrm{H}_{2} \mathrm{O}$ ], assim como pontos na cor preta, possivelmente tratandose de óxido de caracterrística mista (férrico e ferroso) $\left[\mathrm{Fe}_{3} \mathrm{O}_{4}+8 \mathrm{e}^{-}+4 \mathrm{H}_{2} \mathrm{O}\right]$.

Ainda na análise macro, verificando a média total de cada amostra, é possível concluir que as barras se encontram com seção abaixo do diâmetro original de fabricação, de $15,88 \mathrm{~mm}$, com a menor média total lida de $14,464 \mathrm{~mm}$ na amostra B1, diferença de $8,92 \%$ na perda do diâmetro médio total. Contudo, ao analisar cada seção medida, os valores resultantes são ainda mais baixos, como na seção 9 a 135ํำ da amostra B1, que foi obtido o diâmetro de $11,665 \mathrm{~mm}$, o menor encontrado entre as leituras realizadas, perda de $26,54 \%$ comparado ao diâmetro original. 
Todavia, as seções adquiridas por meio do micrômetro de ponta cônica, são resultados de leituras do aço com a crosta de corrosão. Esta camada de oxidação superficial das armaduras mascara a seção real do aço, que é ainda menor, bem como, não apresenta resistência ao material, possuindo característica porosa, com microfissuras e de baixa aderência.

Já na análise microestrutural, a microscopia óptica possibilitou a observação da homogeneidade do material, que apresenta a mesma matriz tanto no núcleo quanto na borda das amostras ensaiadas. Nas bordas, foram encontrados desgastes irregulares, derivado da perda de massa provocada pela corrosão.

Por meio da microscopia eletrônica de varredura, foram encontrados grãos com formato e tamanho característico. Ainda, a crosta oxidada das amostras apresentou profundidade variada, com o maior avanço de corrosão lido de 146,61 $\mu \mathrm{m}$, sendo possível observar nesta camada diversos microvazios e microfissuras, advindos de cerca de 70 anos de envelhecimento natural das armaduras.

\section{Agradecimentos}

Os autores agradecem a infraestrutura e o suporte dos técnicos de laboratórios tanto do Instituto Tecnológico de Aeronáutica (ITA), como também do Instituto de Estudos Avançados (IEAv) e do Instituto Nacional de Pesquisas Espaciais (INPE), que foram de fundamental importância para atingir os objetivos estabelecidos.

\section{Referências}

[1] CARMONA, T. G. Modelos de previsão da despassivação das armaduras em estruturas de concreto sujeitas à carbonatação. Dissertação de mestrado. Escola Politécnica da Universidade de São Paulo (USP). São Paulo, 2005.

[2] GOES, R. S. Galvanização a fogo: o que é e seus benefícios. Palestra pelo Instituto de Materiais Não Ferrosos (ICZ), no Workshop de galvanização a fogo: experiências e aplicações, 2018. Disponível em: http://abraco.org.br/abracocursos/galvanizacao/docs/Apres_Ricardo_Goes.pdf Acesso em: 07 mar. 2019.

[3] MEHTA, P. K.; MONTEIRO, P. J. M. Concrete: microstructure, properties, and materials. 3 ed. New York, NY: McGraw-Hill, 2006.

[4] Padilha, A.F.; Filho, F.A. Técnicas de análise microestrutural. São Paulo: Hemus, 1985.

[5] Silva, A.R. Corrosão em armaduras de espera enterradas com 60 anos - estudo de caso das fundações da Ala Zero do ITA. Dissertação de mestrado. Instituto Tecnológico de Aeronáutica (ITA). São José dos Campos, 2010.

[6] Helene, P.R.L. Contribuição ao estudo da corrosão em armaduras de concreto armado. Tese de Livre Docência. Escola Politécnica da Universidade de São Paulo (USP). São Paulo, 1993. 